\title{
O perfil dos consumidores de e-commerce: um estudo de caso para o município de
}

\section{Dourados (MS)}

\author{
The profile of e-commerce consumers: a case of study for the city of Dourados (MS)
}

El perfil de los consumidores de comercio electrónico: un estudio de caso para la ciudad de Dourados (MS)

Recebido: 25/10/2021 | Revisado: 31/10/2021 | Aceito: 10/01/2022 | Publicado: 17/01/2022

\author{
Matheus Molinari Ferreira \\ ORCID: https://orcid.org/0000-0002-3361-6958 \\ Universidade Federal da Grande Dourados, Brasil \\ E-mail: matheus.molinari.fe@hotmail.com \\ Roselaine Bonfim de Almeida \\ ORCID: https://orcid.org/0000-0002-2195-0035 \\ Universidade Federal da Grande Dourados, Brasil \\ E-mail: roselainealmeida@ufgd.edu.br \\ Jonathan Gonçalves da Silva \\ ORCID: https://orcid.org/0000-0002-1601-8534 \\ Universidade Federal da Grande Dourados, Brasil \\ E-mail: jonathandasilva@ufgd.edu.br
}

\begin{abstract}
Resumo
Este artigo analisa as variáveis que influenciam os consumidores na tomada de decisão entre comprar produtos em lojas físicas ou em lojas virtuais. Para isso, realizou-se uma pesquisa de campo no município de Dourados (MS), onde foram entrevistados 384 indivíduos. Com esses dados, foi realizada uma análise descritiva e econométrica utilizandose o modelo logit, o qual identificou como variáveis estatisticamente significativas o estado civil, a renda e o nível de escolaridade dos indivíduos. Os resultados também mostraram que 58\% dos entrevistados possuem renda entre um salário-mínimo e 2 mil reais. Além disso, pouco mais de $60 \%$ dos entrevistados confiam em realizar compras on-line, esses, no entanto, não se sentem seguros em fornecer seus dados pessoais. Dentre os indivíduos que já realizaram compras on-line, 79\% dos entrevistados, realiza poucas compras e os principais itens adquiridos são, em geral, vestuário e eletrônicos. Os principais fatores motivadores para a realização desse tipo de transação são: preço, comodidade, praticidade e variedade de produtos. Já os fatores desmotivadores são o prazo de entrega e a falta de contato físico com o produto. Ademais, a probabilidade de comprar on-line aumenta em 18,72\% se o indivíduo é solteiro, $9,72 \%$ se o indivíduo possui uma renda entre $\mathrm{R} \$ 1.000,00$ e $\mathrm{R} \$ 2.000,00$ e $18,31 \%$ quando o indivíduo possui ensino superior completo. Com isso, pode-se concluir que apesar do comércio eletrônico ainda gerar certa desconfiança para algumas pessoas, ele teve boa aceitação entre os consumidores Douradenses.
\end{abstract}

Palavras-chave: Comércio eletrônico; Consumidores; Internet.

\begin{abstract}
This article analyzes the variables that influence consumers in making the decision between buying products in physical stores or virtual stores. For this, a field research was carried out in the city of Dourados (MS), through which 384 individuals were interviewed. With these data, a descriptive and econometric analysis was performed using the logit model, which identified as statistically significant variables the individuals' marital status, income and education level. The results also showed that $58 \%$ of respondents have an income between a minimum wage and 2 thousand reais. In addition, just over $60 \%$ of respondents trust to make purchases online, they, however, do not feel secure in providing their personal data. Among individuals who have already shopped online, $79 \%$ of respondents, most make few purchases and the main items purchased are, in general, clothing and electronics. The main motivating factors for carrying out this type of transaction are: price, convenience, practicality and variety of products. The demotivating factors are the delivery time and the lack of physical contact with the product. Furthermore, the probability of buying online increases by $18.72 \%$ if the individual is single, $9.72 \%$ if the individual has an income between BRL $1,000.00$ and BRL 2,000.00 and $18.31 \%$ when the individual has completed higher education. With this, it can be concluded that although e-commerce still generates some distrust for some people, it had good acceptance among Douradense's consumers.
\end{abstract}

Keywords: E-commerce; Consumers; Internet. 


\begin{abstract}
Resumen
Este artículo analiza las variables que influyen en los consumidores a la hora de tomar la decisión entre comprar productos en tiendas físicas o tiendas virtuales. Para ello, se realizó una investigación de campo en la ciudad de Dourados (MS), a través de la cual se entrevistaron 384 personas. Con estos datos se realizó un análisis descriptivo y econométrico mediante el modelo logit, que identificó como variables estadísticamente significativas el estado civil, los ingresos y el nivel educativo de los individuos. Los resultados también mostraron que el 58\% de los encuestados tiene un ingreso entre un salario mínimo y 2 mil reales. Además, poco más del $60 \%$ de los encuestados confía en realizar compras online, sin embargo, no se sienten seguros al facilitar sus datos personales. Entre las personas que ya han comprado online, el $79 \%$ de los encuestados, la mayoría realiza pocas compras y los principales artículos comprados son, en general, ropa y electrónica. Los principales factores motivadores para realizar este tipo de transacciones son: precio, conveniencia, practicidad y variedad de productos. Los factores desmotivadores son el tiempo de entrega y la falta de contacto físico con el producto. Además, la probabilidad de comprar online aumenta un $18,72 \%$ si el individuo es soltero, un $9,72 \%$ si tiene un ingreso entre R \$1.000,00 y R \$2.000,00 y un $18,31 \%$ cuando el individuo ha completado la educación superior. Con esto, se puede concluir que aunque el comercio electrónico aún genera cierta desconfianza en algunas personas, tuvo buena aceptación entre los consumidores Douradenses.
\end{abstract}

Palabras clave: Comercio electrónico; Consumidores; Internet.

\title{
1. Introdução
}

O comércio é uma das atividades mais antigas da sociedade e sua evolução culminou no comércio eletrônico. O comércio eletrônico, também conhecido como e-commerce (abreviação para eletronic commerce) representa toda relação comercial que utiliza algum meio eletrônico. Entretanto, a internet impulsionou ainda mais esse tipo de comércio, uma vez que através dela muitas pessoas estavam conectadas a mesma rede de comunicação, o que aproximou compradores e vendedores. Isso gerou uma verdadeira revolução no mundo dos negócios (Assunção et al., 2019).

De acordo com os dados da Pesquisa Nacional por Amostra de Domicílios Contínua - PNAD Contínua, estima-se que, em 2018, o acesso à internet de pessoas de 10 anos ou mais de idade abrangia 74,7\% da população brasileira. Ao se analisar a faixa etária de 20 a 24 anos esse valor aumentou para 91\%. A principal forma de acesso é o telefone celular móvel, que foi utilizado por $98,1 \%$ das pessoas (Instituto Brasileiro de Geografia e Estatística [IBGE], 2018). Conforme Assunção et al. (2019) esses dados apontam que o comércio eletrônico deve utilizar os telefones celulares como principal estratégia de venda, dado que ele é o principal meio utilizado pelos consumidores para acessar a internet.

Segundo a $42^{a}$ edição do relatório Webshoppers, realizado pela empresa E-bit no ano de 2020, o comércio eletrônico não parou de crescer desde a década de 2000. Entretanto, no primeiro semestre de 2020 o comércio eletrônico brasileiro atingiu a marca de $\mathrm{R} \$ 38,8$ bilhões em vendas, com um crescimento de 47\% em relação ao semestre anterior. Esse crescimento se intensificou principalmente devido a pandemia da Covid-19, que levou muitos brasileiros a optar pelas compras on-line (Ebit, 2020). Em 2020 houve um crescimento, em relação ao ano anterior, de $23 \%$ no número de novos consumidores, que tinham um ticket médio no valor de $\mathrm{R} \$ 452$ reais (Ebit, 2021).

Nesse sentido, para uma melhor compreensão desse mercado este artigo analisa os fatores que influenciam os consumidores na tomada de decisão entre comprar bens e serviços em lojas físicas ou em lojas virtuais. Com isso, será possível traçar um perfil dos consumidores que realizam compras on-line. A análise foi realizada em uma cidade de porte médio, Dourados, no estado de Mato Grosso do Sul (MS). A escolha desse município se justifica porque há poucos trabalhos que analisam o perfil dos consumidores de cidades de pequeno e médio porte, sobretudo quando o tema é o comércio on-line. Dessa forma, a cidade de Dourados foi escolhida como um caso representativo, cujos resultados poderão, eventualmente, ser generalizados para representar municípios com características semelhantes.

Para isso, foi realizado um levantamento e análise dos trabalhos já publicados, visando compreender o comportamento do consumidor on-line. Além disso, com os dados coletados na pesquisa de campo foi possível utilizar o modelo econométrico Logit e identificar as características individuais que afetam a probabilidade de o indivíduo optar por comprar um produto online ou em uma loja física. Espera-se com isso, gerar insumos para uma melhor compreensão das desconfianças que levam os 
consumidores a não realizarem compras on-line e, também, compreender os fatores que favorecem a realização dessas compras.

Este trabalho está organizado em seis seções, incluindo esta introdução. $\mathrm{Na}$ seção 2 apresenta-se a revisão bibliográfica, demonstrando os principais aspectos da internet, e, consequentemente, apresenta a evolução e consolidação do comércio eletrônico. A seção 3 apresenta a metodologia de estudo. Na quarta seção tem-se a análise descritiva dos dados obtidos na aplicação dos questionários e, em seguida, os resultados da aplicação do modelo econométrico Logit. A seção 5 é dedicada às considerações finais do trabalho. Por fim, apresenta-se as referências utilizadas para embasamento deste artigo.

\section{Revisão Bibliográfica}

No mundo atual a internet faz parte do dia a dia das pessoas, que a utilizam para ler notícias, trocar mensagens, assistir vídeos, fazer compras, entre outras atividades. Entretanto, a internet que conhecemos hoje foi originalmente desenvolvida como uma forma de comunicação entre militares do Departamento de Defesa Americano. Em 1957 o presidente dos Estados Unidos da América, Dwinght Eisenhower, criou a Advanced Research Projects Agency (ARPA), que tinha o papel de desenvolver esse sistema de comunicação. Em 1969 a ARPA consegue fazer a interligação das máquinas, criando a ARPANET, que era uma rede de computadores que futuramente originou a internet. Em 1973 a ARPANET consegue realizar a primeira conexão internacional entre dois países (Inglaterra e Noruega). Entretanto, o termo "Internet" surgiu apenas em 1974 (Almeida, 2015).

Seguindo com o seu significativo avanço, em 1980 o britânico Tim Berners-Lee lança a ideia do World Wide Web $(w w w)$, a qual só se concretizou quando, em 6 de agosto de 1991, ele compartilhou seu projeto em um grupo de notícias chamado alt.hypertext. Desde então, a internet tornou-se livre para todos. Como um veículo de multimídia e comunicação em massa e com um crescimento intenso, em 1995, a internet já atingia a marca de 16 milhões de usuários conectados. Seis anos depois, essa marca ultrapassava os 400 milhões de usuários (Castells, 2003).

Com a evolução da tecnologia e da internet surge o comércio eletrônico, que chegou com o objetivo de complementar e facilitar o processo de venda, quebrando as barreiras da globalização e firmando parcerias entre empresas e, dessa forma, diminuindo cada vez mais os limites geográficos (Figueiredo, 2009). Diante desse avanço extremamente rápido, as preferências dos consumidores também se alteraram. Em 1994 ocorreu a primeira venda da história na internet. O item vendido foi uma pizza, comercializada pela empresa Pizza Hut (Novaes \& Gregores, 2007).

No Brasil, as primeiras lojas on-line começaram a funcionar na segunda metade dos anos 1990. Dentre elas, pode-se destacar grandes companhias como Ponto Frio, Americanas, Shoptime, Submarino, Netshoes, entre outras (Galinari et al., 2015). Entretanto, diante da evolução das telecomunicações, o comportamento e a preferências dos consumidores se alteraram com o passar dos anos e se adequaram ao ambiente em que estavam inseridos. Como forma de tentar explicar essa mudança, podemos utilizar a teoria Neoclássica. Essa teoria considera o indivíduo como um agente econômico racional que busca maximizar sua utilidade. A utilidade é representada pela satisfação obtida ao se consumir uma mercadoria, dessa forma, quanto maior o consumo da mercadoria, maior será a utilidade (Varian, 2021).

Para tanto, o consumidor deve respeitar sua restrição orçamentária, onde de acordo com Hall e Liberman (2003 p. 140) "uma restrição no orçamento do consumidor identifica quais combinações de bens e serviços o consumidor pode comprar com um orçamento limitado, a preços determinados". Assim, o consumidor se depara com um trade-off constantemente, pois ele tem que decidir entre uma mercadoria ou outra para completar sua cesta de bens. Dessa forma, ao longo do seu processo de decisão normalmente o consumidor precisa abrir mão de uma mercadoria para poder consumir outra, o que acaba gerando um custo de oportunidade (Mankiw, 2020). 
Logo, o princípio da teoria do consumidor tem como base que o indivíduo sempre irá adquirir a melhor cesta, ou seja, a cesta que maximizará sua satisfação, sujeita a sua restrição orçamentária (Varian, 2021). Dado que as preferências dos consumidores se alteram não só com o ambiente em que estão inseridos, mas, também, por aspectos culturais, pessoais, psicológicos e, principalmente, sociais, conforme Mansfield e Yohe (2006, p. 31), "os gostos do consumidor certamente podem ser alterados pela experiência". Dessa forma, os e-consumidores possuem o feedback dos outros compradores com apenas um clique, adquirindo experiências antes mesmo de realizar a compra do produto desejado.

Além do feedback dos outros usuários, seja do produto ou da loja, outro ponto importante na decisão de compra dos econsumidores são as propagandas utilizadas para divulgação do produto ou da loja, que muitas vezes possuem técnicas de marketing direcionado, onde tomam proveito das tendências de escolha de cada consumidor. De acordo com Varian (2021) essas técnicas também são conhecidas como efeitos de contexto. Nestes casos, nem mesmo um feedback negativo de outro consumidor pode afetar sua decisão de compra, pois o indivíduo possui um viés muito grande sobre o produto ou loja.

Dessa forma, de acordo com Costa (2007) a internet está se tornando um ponto chave na infraestrutura de tecnologia da informação e, com isso, auxiliando muitas empresas a reestruturar-se e renovar os seus tipos de negócios e processos internos, facilitando também o processo de conquista e fidelização de seus clientes. Isso acontece porque, com o comércio online, essas empresas podem obter feedbacks dos compradores, podendo assim, medir sua reputação e corrigir as falhas apontadas.

Um dos fortes diferenciais que aumentam a produtividade de uma loja on-line está diretamente ligada à esfera dos custos, pois, se compararmos ao varejo de loja física, o investimento em uma estrutura de e-commerce é relativamente menor devido aos ativos físicos como, por exemplo, imóvel, estacionamento e aquisição de mobília. Além disso, para realizar suas atividades o e-commerce necessita de um número de funcionários relativamente menor que as lojas físicas, visto que não há necessidade de se manter uma equipe de vendas, pagamento de comissões e outra para caixa e recebimentos (Galinari et al., 2015).

Além da redução de custos em ativos físicos, o e-commerce também proporciona redução nos custos de transporte e de estocagem de mercadorias. Ao contrário das varejistas físicas, que possuem despesas de loja e de estoque, a loja on-line pode manter poucos centros de distribuição, muitas vezes até no mesmo prédio da sua central de controle e gerência, o que simplifica o processo de administração de estoques e agiliza o processo de entrega do produto. Há também novos modelos de negócios que transacionam produtos digitais como músicas, filmes e séries, produção de imagens e vídeos, e-books e revistas, softwares, etc. Esse nicho de e-commerce praticamente não possui custo com transporte e estoque (Galinari et al., 2015).

Dessa forma, a redução de custos é muito importante para qualquer empresa, seja ela de atuação física ou on-line, pois para que haja lucro, a empresa precisa atuar acima da igualdade entre a soma de vendas e a soma de despesas. Entretanto, a redução de custos deve ser realizada de forma que não haja a redução da satisfação do consumidor (Angelo \& Silveira, 2000).

As vantagens do e-commerce não se concentram apenas à esfera dos custos, afinal, ele também potencializa significativamente as vendas, pois a loja on-line não possui limitações geográficas, quando comparadas as lojas físicas, que concentram suas vendas em uma área próxima ao seu estabelecimento, como bairros, cidade e região. Já a loja on-line consegue atender todo o país e até mesmo outros países. Além das esferas custos e limitações geográficas, existe também a esfera tempo, onde o e-commerce permanece ativo as 24 horas do dia, sem precisar de uma grande quantidade de funcionários ativos o tempo todo, simplificando a vida do e-consumidor com tempo escasso e possibilitando a venda de seus produtos a qualquer hora do dia (Galinari et al., 2015).

Visto as vantagens do e-commerce para o empresário, é natural refletir sobre algumas delas para o e-consumidor. Uma das maiores vantagens das lojas on-line é o consumidor ter acesso a uma infinidade de produtos sem precisar sair de casa (Pitwak \& Ferreira, 2009). 
Além dos clientes conseguirem realizar as compras no conforto de sua residência, eles podem adquirir um produto a qualquer hora do dia e de qualquer lugar do país ou do mundo. Do conforto de suas resistências ainda dispõem de uma grande variedade de produtos e, realizando uma breve pesquisa os e-consumidores encontram o site com o menor preço para o produto desejado, com a melhor reputação e contato com outros consumidores que já possuem o produto, o que pode proporcionar um feedback mais preciso. Dessa forma, o cliente encontra todas essas informações sobre o produto sem precisar gastar com deslocamento, estacionamento e perder muito tempo entrando em várias lojas à procura do menor preço (Testa et al., 2006).

Entretanto, o comércio on-line possui algumas desvantagens perante as lojas físicas, como a preferência dos consumidores em ver pessoalmente o produto, tocá-lo e experimentá-lo antes de realizar a compra. Outra dificuldade para o $e$ commerce está relacionada a segurança das transações on-line, pois, para fechar um pedido o cliente precisa informar seus dados pessoais, número de cartões de crédito e senhas. Isso pode deixar o cliente inseguro já que em uma compra on-line sabese muito pouco sobre a identidade real de quem está do outro lado da tela. Além disso, o número crescente de fraudes virtuais, que prejudicam tanto a empresa quanto o consumidor, também gera insegurança nas transações (Pitwak \& Ferreira, 2009).

Mais adiante, o desafio chega na entrega do produto, que deve ser rápida e o produto deve chegar em bom estado. Para que isso aconteça, a loja deve possuir um gerenciamento de estoque rápido e preciso para separar os produtos de cada pedido e embalar de forma adequada, evitando assim, que ocorra algum imprevisto durante o transporte e seja necessário realizar a troca do produto (Turban et al., 2003).

Após apresentar a evolução do e-commerce e as principais vantagens e desvantagens desse tipo de comércio, é importante analisar na literatura os estudos aplicados a esse tema. Siqueira (2004) realizou um estudo analisando, primeiramente, os custos que uma loja varejista gera para atuar no mercado. Em seu trabalho ele busca alternativas para reduzir esses custos e, uma delas, foi o direcionamento dos clientes para o atendimento pela internet, o que geraria maior eficiência operacional dos custos da loja, sem perda da aceitação do cliente. Para isso, o autor realizou uma pesquisa de campo na cidade de São Paulo, que contou com 408 entrevistados, que foram separados por regiões (norte, sul, leste e oeste) e por faixa de renda (alta, média e baixa).

Após a coleta e análise dos dados o autor concluiu que, do ponto de vista da oferta, a venda on-line possibilita benefícios de economia de escala e redução de custos, principalmente operacionais e de logística. Porém, do ponto de vista da demanda, existem vários obstáculos. O principal está na aceitação do $e$-commerce pelos cidadãos paulistanos, evidenciando a falta de alinhamento entre os consumidores e as empresas.

Costa e Ruiz (2011) analisaram as alterações no padrão de consumo no Brasil comparando o e-commerce e as lojas físicas. Os autores concluíram que apesar das dificuldades estruturais enfrentadas pelas empresas no Brasil, o comércio eletrônico continua crescendo. Entretanto, algumas empresas ainda precisam adaptar-se ao novo método de vendas. Visando demonstrar o atraso no desenvolvimento dessas empresas, em relação ao mundo virtual, os autores analisaram a usabilidade da internet como ferramenta de vendas e todo o marketing embarcado na mesma e concluíram que o comércio eletrônico não está crescendo para acabar com as vendas das lojas físicas, pois há lugar para todos no mercado.

Vieira (2010) realizou um estudo buscando mensurar a qualidade do serviço no varejo eletrônico e seu impacto sobre as intenções comportamentais dos consumidores, onde o autor aplicou um questionário em uma amostra de 515 internautas que haviam realizado compras on-line nos últimos seis meses. Após a análise dos dados, o autor concluiu que para que a empresa receba uma avaliação positiva do consumidor, é necessário que o site tenha uma boa segurança e privacidade das informações dos seus usuários, gerando assim maiores chances de retorno.

Macedo et al. (2013) realizaram um estudo cujo objetivo era a identificação do perfil do e-consumidor entre os acadêmicos de Administração da Universidade Estadual de Ponta Grossa - UEPG. Os autores realizaram uma pesquisa de 
campo com uma amostra de 240 acadêmicos $^{1}$ e com um questionário que continha 13 questões abertas e fechadas. Após análise dos dados obtidos, os autores observaram que os acadêmicos mais jovens, entre 16 e 25 anos, e com menor nível de renda, entre $\mathrm{R} \$ 260,00$ e $\mathrm{R} \$ 1.300,00$, foram os que mais compraram pela internet. Além disso, do total de compradores, a maioria realiza compras anualmente e o principal meio de pagamento é o cartão de crédito. O critério identificado como decisivo para a finalização da compra foi o preço, e a não realização da compra está relacionada com a insegurança e visualização da qualidade do produto a ser adquirido.

Visto o crescimento do e-commerce no Brasil é natural que problemas o acompanhem. Diante disso, Coelho et al. (2013) desenvolveram uma pesquisa com o objetivo de identificar, na visão dos clientes, oportunidades de melhoria no comércio eletrônico. Para isso, realizaram uma pesquisa de campo com uma amostra de 70 pessoas que tinham realizado compras no site da empresa estudada em outubro de 2012. Após a coleta e análise dos dados, os autores chegaram à conclusão de que os principais problemas do site estudado eram as falhas nos sistemas de informações e distribuição, onde a entrega registrou $45 \%$ dos problemas relatados.

De acordo com Galinari et al. (2015) o comércio varejista vem experimentando grandes transformações. Os autores analisaram os principais determinantes do comércio eletrônico no Brasil e suas variações, surgidas com o avanço tecnológico. No final da pesquisa os autores concluíram que o comércio eletrônico brasileiro, entre os anos de 2005 e 2014 , cresceu a elevadas taxas e os fatores que contribuíram para esse crescimento foram: as melhorias nos sistemas de telecomunicações e infraestrutura, inclusão social, disseminação de dispositivos conectados à internet e, também, as mudanças comportamentais dos consumidores.

Os estudos apresentados mostram a evolução do comércio eletrônico no Brasil e suas principais vantagens e desvantagens, tanto para o consumidor quanto para a empresa. Entretanto, como foi observado, esses estudos se limitam a uma análise descritiva dos dados. Dessa forma, este trabalho se insere nessa literatura por também analisar as variáveis que impactam na decisão do consumidor entre comprar produtos em lojas físicas ou em lojas virtuais. Entretanto, o estudo avança ao fazer uma análise quantitativa desses dados.

\section{Metodologia}

Este artigo tem como objetivo analisar os determinantes que influenciam os consumidores na decisão entre comprar bens e serviços em lojas físicas ou em lojas virtuais. Para isso, foi realizado um estudo de caso na cidade de Dourados (MS). Conforme Freire e Pattussi (2018) o estudo de caso representa a forma mais básica de estudo descritivo. Ele costuma ser utilizado para fazer uma avaliação inicial de problemas pouco conhecidos e que não tiveram suas características amplamente esmiuçadas.

Dessa forma, este trabalho pode ser classificado como um estudo de caso porque realizou uma pesquisa de campo com os consumidores do município de Dourados (MS), com o intuito de identificar as preferências de consumo e o perfil dos e-consumidores douradenses que optam pelo comércio eletrônico, perfil que ainda é pouco conhecido. Nesta seção será apresentada a fonte de dados e o modelo logit.

\subsection{Fonte de Dados}

O objetivo principal deste artigo foi identificar os fatores que levam os consumidores a optar pelo comércio eletrônico ou pela compra em lojas físicas. Para isso, utilizou-se dados primários, que foram coletados no município de Dourados (MS). Dessa forma, ao longo dos meses de abril e maio de 2018, foi aplicado um questionário para uma amostra selecionada. Parte

\footnotetext{
${ }^{1}$ Entretanto, apenas 101 acadêmicos responderam os questionários.
} 
dos questionários foram aplicados na Praça Antônio João e a outra parte no Parque dos Ipês, ambos no município de Dourados (MS).

Essa divisão foi feita porque acredita-se que os dois locais possuem consumidores com perfis diferentes. A hipótese aqui é que provavelmente os consumidores que frequentam o Parque dos Ipês tenham um nível de renda maior, o que pode influenciar a sua forma de consumir. Portanto, com o intuito de ter uma amostra mais variada optou-se pela aplicação do questionário em lugares diferentes, assim como Siqueira (2004) fez em seu estudo para o município de São Paulo. Em seu trabalho ele separou sua amostra em três faixas de renda: baixa, média e alta.

$\mathrm{O}$ objetivo da pesquisa foi analisar o perfil e a escolha do consumidor douradense através de um questionário formado por 18 questões de múltipla escolha. O questionário foi elaborado com base na literatura sobre o tema. $\mathrm{O}$ universo em que este estudo foi realizado é constituído pela população acima de 16 anos da cidade de Dourados (MS).

Dentre as 18 questões, o questionário divide-se em duas seções. Na primeira são realizadas perguntas de ordem pessoal, caracterizando o indivíduo a partir do seu gênero, sua idade, cor ou raça, estado civil, escolaridade e faixa de renda. Em seguida, são colocadas 3 questões sobre sua confiança em realizar compras pela internet e, na sequência, a questão 10 separa quem já realizou compras no comércio eletrônico de quem nunca realizou. Os participantes que responderam que nunca realizaram compras on-line podem responder à questão 11 , que questiona o motivo da não realização de compras no ecommerce, e finalizar o questionário.

Para os participantes que realizam compras on-line, a questão 11 não aparece e eles seguem para a segunda seção do questionário, respondendo a mais 6 questões sobre a frequência de compras, categoria de produtos já adquiridos, tempo médio de utilização da internet ao dia, valor médio gasto por compra, fatores que os induzem a realizar compras no e-commerce e as vantagens e desvantagens desse tipo de comércio.

Para o cálculo da amostra foi utilizada a seguinte fórmula (Hoffmann, 2006):

$$
n=\frac{Z^{2} \cdot \hat{p} \hat{q}}{e^{2}}
$$

onde:

$\mathrm{n}=$ tamanho da amostra.

$\mathrm{Z}^{2}$ = é o nível de confiança desejado, ou seja, $95 \%=1,96$.

$\mathrm{e}^{2}=$ é a margem de erro máxima, ou seja, $5 \%$.

$\hat{p}=0,5$

$\widehat{q}=1-\hat{p}$

Logo: $n=\frac{(1,96)^{2} \cdot 0,5 \cdot(1-0,5)}{0,05^{2}}=384,16$.

Portanto, a amostra é composta de 384 douradenses, sendo que 192 foram entrevistados na Praça Antônio João e 192 no Parque dos Ipês.

\subsection{O Modelo Logit}

O objetivo principal deste artigo é analisar os determinantes que influenciam os consumidores na tomada de decisão entre comprar bens e serviços em lojas físicas ou em lojas virtuais, ou seja, pretende-se identificar quais características individuais afetam a probabilidade de um indivíduo optar por comprar um produto pela internet, ao invés de comprar esse produto em uma loja física. Para isso, utilizou-se uma amostra de dados da cidade de Dourados (MS).

Para a construção do modelo observa-se que a variável dependente, Y, é uma variável binária. Dessa forma, se $\mathrm{Y}=1$, então o indivíduo já realizou compras pela internet e, se $\mathrm{Y}=0$, então o indivíduo nunca realizou compras pela internet. De 
acordo com Wooldridge (2016), quando temos uma variável dependente binária podemos utilizar um modelo de resposta binária para determinar o efeito das variáveis independentes sobre a probabilidade de resposta da variável dependente. Para fazer isso, neste artigo utilizaremos o modelo de regressão logística, mais conhecido como logit.

Segundo Gujarati (2006, p.480), o modelo logit pode ser apresentado como segue:

$$
P i=E(Y=1 \mid X i)=\frac{1}{1+e^{-\left(\beta_{1}+\beta_{2} X i\right)}}
$$

no qual:

$P i=$ Probabilidade de realizar compras on-line

$\beta_{1}=$ constante;

$\beta_{2}=$ coeficiente da variável $\mathrm{i}$

$X i=$ variáveis explicativas (gênero, cor, idade, estado civil, renda e escolaridade).

Conforme Gujarati (2006, p.481), a equação (2) pode ser simplificada como na equação (3):

$$
\mathrm{P} i=\frac{1}{1+\mathrm{e}^{-\mathrm{Zi}}}=\frac{\mathrm{e}^{\mathrm{z}}}{1+\mathrm{e}^{\mathrm{z}}}
$$

no qual: $\mathrm{Zi}=\beta_{1}+\beta_{2} \mathrm{X} i$

Essa equação é conhecida como função de distribuição logística (acumulada). De acordo com Gujarati (2006), os valores de $\mathrm{Z}$ podem variar entre $-\infty$ e $+\infty$. Além disso, o valor de Pi situa-se entre 0 e 1 , estando de acordo com as condições da função de distribuição logística.

Ainda de acordo com Gujarati (2006, p.481), como Pi não é linear nos valores de X e dos $\beta$ 's (identificados em Z), torna-se impossível obter um melhor ajustamento utilizando o método dos Mínimos Quadrados Ordinários (MQO). Dessa forma, é indispensável a aplicação da linearidade na equação (2). Assim, se $P i$ é a probabilidade de o indivíduo realizar compras utilizando o comércio eletrônico, do contrário temos $(1-P i)$, que representa a probabilidade de o indivíduo não ter realizado compras utilizando o comércio eletrônico, sendo:

$$
1-P i=\frac{1}{1+e^{Z i}}
$$

Logo, podemos reescrever essa equação como abaixo:

$$
\frac{P_{i}}{1-\mathrm{Pi}}=\frac{1+\mathrm{e}^{\mathrm{Zi}}}{1+\mathrm{e}^{-\mathrm{Zi}}}=\mathrm{e}^{\mathrm{Zi}}
$$

A equação (5) representa a razão das chances de o indivíduo já ter realizado compras utilizando o comércio eletrônico em paralelo ao indivíduo que não utiliza o comércio eletrônico (1/1-Pi).

No entanto, calculando o logaritmo natural da equação (5), temos: 


$$
\mathrm{L} i=\ln \left(\frac{\mathrm{P} i}{1-\mathrm{P} i}\right)=\mathrm{Z} i
$$

Ao utilizar o logaritmo natural, a razão entre as chances passa a ser linear tanto para os parâmetros da equação, quanto para as variáveis independentes. O modelo logit é representado pela equação Li.

Entretanto, vale ressaltar que a análise não termina aqui. Ainda é preciso encontrar o efeito marginal de cada variável independente. Segundo Wooldridge (2016, p. 650) "Para encontrar o efeito parcial de variáveis, aproximadamente contínuas, temos de confiar no cálculo. Se $x_{j}$ for uma variável aproximadamente contínua, seu efeito parcial sobre $p(x)=P(y=1 \mid x)$ será obtido da derivada parcial". Dessa forma, para encontrar o efeito marginal de cada variável é necessário derivar a função de distribuição cumulativa. Seu resultado será a função de densidade de probabilidade, ou seja, o efeito marginal. Os cálculos foram realizados através do programa Stata.

\section{Resultados e Discussão}

Esta seção está dividida em duas subseções. Na primeira apresenta-se a análise descritiva dos dados coletados e na segunda subseção são apresentados os resultados do modelo logit.

\subsection{Análise Descritiva dos Dados}

Esta subseção apresenta os principais resultados encontrados com os dados da amostra coletada na cidade de Dourados (MS). A Tabela 1 mostra como esses indivíduos estão distribuídos dentro da amostra. 
Tabela 1 - Distribuição das características dos consumidores entrevistados em Dourados, em 2018, em porcentagem.

\begin{tabular}{|c|c|c|}
\hline \multicolumn{2}{|r|}{ Característica } & $\%$ \\
\hline \multirow{2}{*}{ Sexo } & Masculino & 50,3 \\
\hline & Feminino & 49,7 \\
\hline \multirow{5}{*}{ Cor ou raça } & Parda & 21,9 \\
\hline & Branca & 61,5 \\
\hline & Preta & 14,3 \\
\hline & Amarela & 1,6 \\
\hline & Indígena & 0,8 \\
\hline \multirow{5}{*}{ Estado Civil } & Solteiro & 48,4 \\
\hline & Separação Legal (Judicial ou Divórcio) & 3,4 \\
\hline & Casado & 42,0 \\
\hline & Viúvo & 5,7 \\
\hline & Outro & 0,3 \\
\hline \multirow{7}{*}{ Faixa Etária } & $16-18$ & 8,9 \\
\hline & $18-20$ & 16,7 \\
\hline & $20-25$ & 17,4 \\
\hline & $25-30$ & 14,6 \\
\hline & $30-40$ & 15,4 \\
\hline & $40-60$ & 16,4 \\
\hline & Mais de 60 & 10,7 \\
\hline \multirow{7}{*}{ Escolaridade } & Ensino Fundamental Incompleto & 2,9 \\
\hline & Ensino Fundamental Completo & 9,4 \\
\hline & Ensino Médio Incompleto & 2,9 \\
\hline & Ensino Médio Completo & 26,0 \\
\hline & Ensino Superior Incompleto & 25,8 \\
\hline & Ensino Superior Completo & 21,1 \\
\hline & Pós-graduação & 12,0 \\
\hline \multirow{5}{*}{ Faixa de Renda } & Até $\mathrm{R} \$ 1.000,00$ & 29,4 \\
\hline & De $R \$ 1.000,00$ a $R \$ 2.000,00$ & 28,6 \\
\hline & De $\mathrm{R} \$ 2.000,01$ a $\mathrm{R} \$ 3.000,00$ & 17,2 \\
\hline & De $R \$ 3.000,01$ a $R \$ 5.000,00$ & 13,8 \\
\hline & Maior que R\$5.000,01 & 10,9 \\
\hline
\end{tabular}

Fonte: Elaborado pelos autores com base nos dados da pesquisa.

Dos indivíduos participantes da pesquisa, 49,7\% eram do sexo feminino e 50,3\% do sexo masculino, ou seja, em relação ao gênero, a amostra está bem distribuída. A maioria dos indivíduos se autodeclarou como branco (61,5\%), em seguida, como pardo e afrodescendente, $21,9 \%$ e 14,3\% dos participantes, respectivamente. Os indivíduos que se autodeclararam como amarelos e indígenas representam, respectivamente, 1,6\% e 0,8\% da amostra. Com relação ao estado civil, a maioria dos participantes estão solteiros (48,4\%), o que é seguido pelos casados (42\%), viúvos (5,7\%), separados legalmente (judicial ou divórcio) $(3,4 \%)$ e pelos que responderam outro $(0,3 \%)$, respectivamente.

Com relação à idade, foram apresentados alguns intervalos etários aos participantes para que se autoidentificassem, conforme a Tabela 1. Os dados obtidos foram relativamente próximos, assim, concluiu-se que a pesquisa atingiu um público de faixas etárias distintas. A Tabela 1 também apresenta a escolaridade dos participantes. Observa-se que a maior parte está concentrada em três categorias: Ensino Médio Completo (26\%), Superior Incompleto (25,8\%) e Superior Completo (21,1\%). 
Em seguida, com 12\% da amostra, tem-se os participantes com Pós-Graduação. Já os participantes com Ensino Fundamental Completo representam 9,4\% da amostra, enquanto os participantes com os Ensinos Médio e Fundamental Incompleto representam $2,9 \%$ cada.

Por último, a Tabela 1 apresenta a variável renda, que foi dividida em 5 faixas. É importante observar que o percentual de indivíduos presentes em cada faixa de renda diminuía à medida que essa aumentava. Dessa forma, a primeira faixa, de até $\mathrm{R} \$ 1.000,00$, responde por $29,4 \%$ dos entrevistados. A segunda faixa de renda responde por $28,6 \%$ dos entrevistados, a terceira faixa de renda responde por $17,2 \%$ dos entrevistados, a quarta faixa de renda responde por $13,8 \%$ dos entrevistados e a última faixa de renda, maior que $\mathrm{R} \$ 5.000,01$, responde por 10,9\% dos entrevistados pela pesquisa.

Além das perguntas sobre as características pessoais dos indivíduos, o questionário também apresentou algumas questões relacionadas à confiabilidade no comércio eletrônico. Para responder o questionário os participantes da pesquisa atribuíram notas de 1 a 5 às suas respostas, sendo 1 utilizado para expressar menor grau de confiança e 5 para expressar maior grau de confiança. Esses resultados são apresentados na Tabela 2.

Tabela 2 - Grau de Confiança nas transações on-line, de 1 a 5, em porcentagem, em 2018.

\begin{tabular}{l|c|c|c|c|c}
\cline { 2 - 6 } & \multicolumn{1}{c}{ Nota } \\
\cline { 2 - 6 } & $\mathbf{1}$ & $\mathbf{2}$ & $\mathbf{3}$ & $\mathbf{4}$ & $\mathbf{5}$ \\
\hline Confiança na realização de compras on-line & 5,47 & 8,85 & 22,92 & 35,68 & 27,08 \\
\hline $\begin{array}{l}\text { Confiança no fornecimento de dados } \\
\text { pessoais em compras on-line }\end{array}$ & & & & & \\
\hline Confiança na entrega do produto & 22,65 & 20,31 & 22,4 & 23,2 & 11,46 \\
\hline
\end{tabular}

Fonte: Elaborado pelos autores com base nos dados da pesquisa.

A partir dos dados, pode-se concluir que a maioria dos participantes confiam nas compras on-line. Isso porque $35,68 \%$ deles atribuíram nota 4 a esse quesito e 27,08\% atribuíram nota 5. Com relação à confiança no fornecimento de dados pessoais, pode-se observar que a amostra está bem dividida. Os participantes que atribuíram nota 1 representam 22,65\% da amostra enquanto os que atribuíram nota 2 representam 20,31\%. Os participantes que atribuíram nota 3 representam 22,4\% dos entrevistados e os que atribuíram nota 4 representam $23,2 \%$ dos entrevistados. Por fim, os participantes que confiam plenamente na realização de compras on-line, nota 5 , representam $11,46 \%$ da amostra.

Quando questionados sobre a confiança na entrega dos produtos, 34,64\% dos participantes responderam que confiam plenamente na entrega, enquanto $32,8 \%$ dos participantes atribuíram nota 4, o que ainda mostra certa confiança na entrega. Na sequência, 21,4\% estavam relativamente indecisos, atribuindo nota 3 como resposta a essa pergunta. Apenas 4,9\% não confiam na entrega dos produtos.

Após responder perguntas sobre aspectos pessoais e o grau de confiança nas compras on-line, os participantes da pesquisa responderam o seguinte questionamento: Você já realizou compras pela internet? Essa é a pergunta que separa quem já realizou pelo menos uma compra no comércio eletrônico de quem nunca realizou. Assim, 79,4\% (305 indivíduos) dos participantes responderam que já realizaram alguma compra on-line, enquanto 20,6\% (79 indivíduos) responderam que nunca realizaram compras on-line.

A Figura 1 apresenta os principais motivos para a não realização de compras on-line. Para essa questão, os participantes podiam marcar mais de um item. Como se observa, a maioria dos indivíduos (51 pessoas) não realizou compras on-line por receio de que o produto não fosse entregue. O segundo motivo mais votado pelos participantes da pesquisa foi a falta de confiança no fornecimento dos dados pessoais (47 pessoas). Além disso, para 42 participantes, o motivo principal é a 
falta de contato físico com o produto. Cabe destacar que apenas 2 participantes responderam que não compraram produtos online porque não tinham acesso à internet.

Figura 1 - Motivos citados pelos entrevistados em Dourados para a não realização de compras pela internet em 2018.

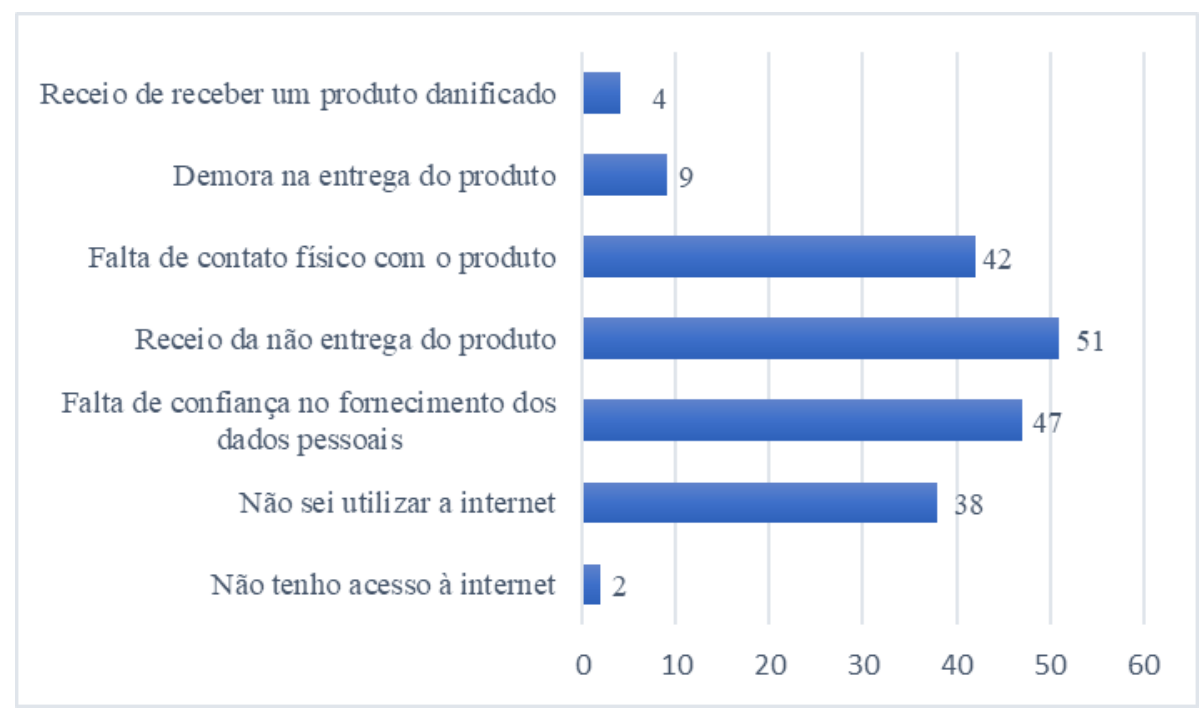

Fonte: Elaborado pelos autores com base nos dados da pesquisa.

No que se refere à frequência de compras on-line, a Figura 2 mostra que 158 participantes, 51,8\% dos indivíduos que já compraram on-line, responderam que realizam compras pela internet poucas vezes ao ano, enquanto 80 participantes, $26,2 \%$, responderam que realizam compras uma vez ao mês. Já os participantes que compram pela internet mais de uma vez ao mês somam 58 indivíduos, enquanto os que compram apenas uma vez ao ano totalizam 9 indivíduos, o que representa 2,9\% desse grupo.

Figura 2 - Frequência de compras on-line entre os indivíduos entrevistados em Dourados, em 2018.

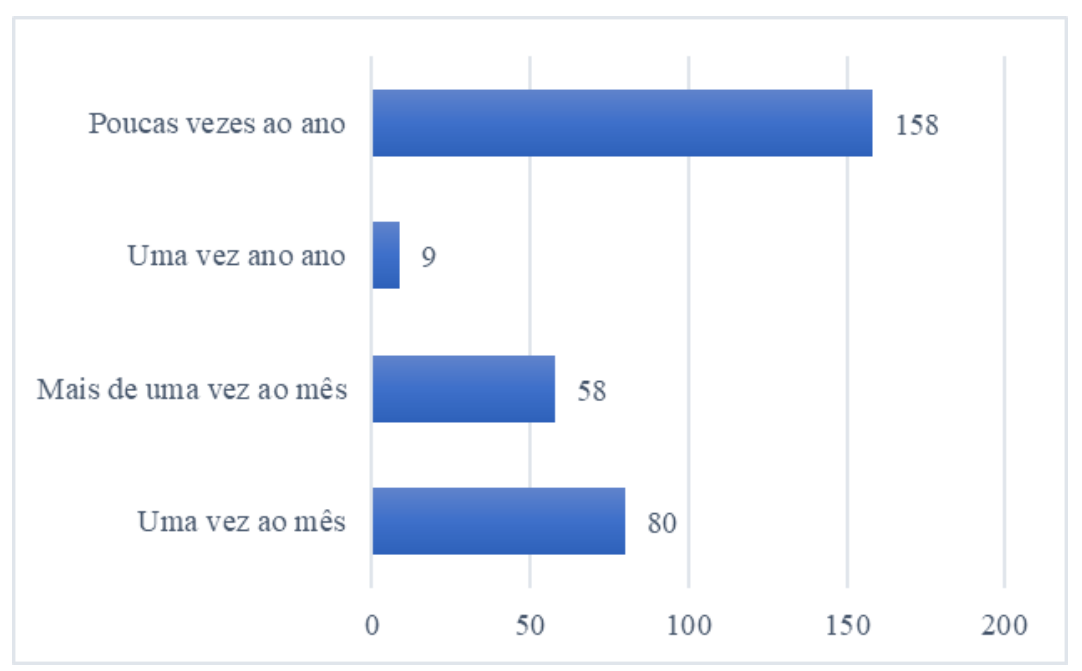

Fonte: Elaborado pelos autores com base nos dados da pesquisa.

Na pesquisa realizada, os produtos preferidos nas compras on-line são vestuário e eletrônicos com, respectivamente, 231 e 196 marcações cada, o que corresponde a 75,7\% e 64,2\% dos entrevistados, respectivamente. A categoria livros e revistas foi assinalada por 146 participantes, representando 47,8\% da amostra. Já a categoria saúde e beleza foi escolhida por 
141 entrevistados, o que corresponde a 46,2\% da amostra e, por último, a categoria "eletrodomésticos" foi assinalada 129 vezes, correspondendo a $42,2 \%$ da amostra, conforme a Figura 3.

Figura 3 - Categoria de produtos comprados no comércio eletrônico pelos entrevistados em Dourados, em 2018, números absolutos.

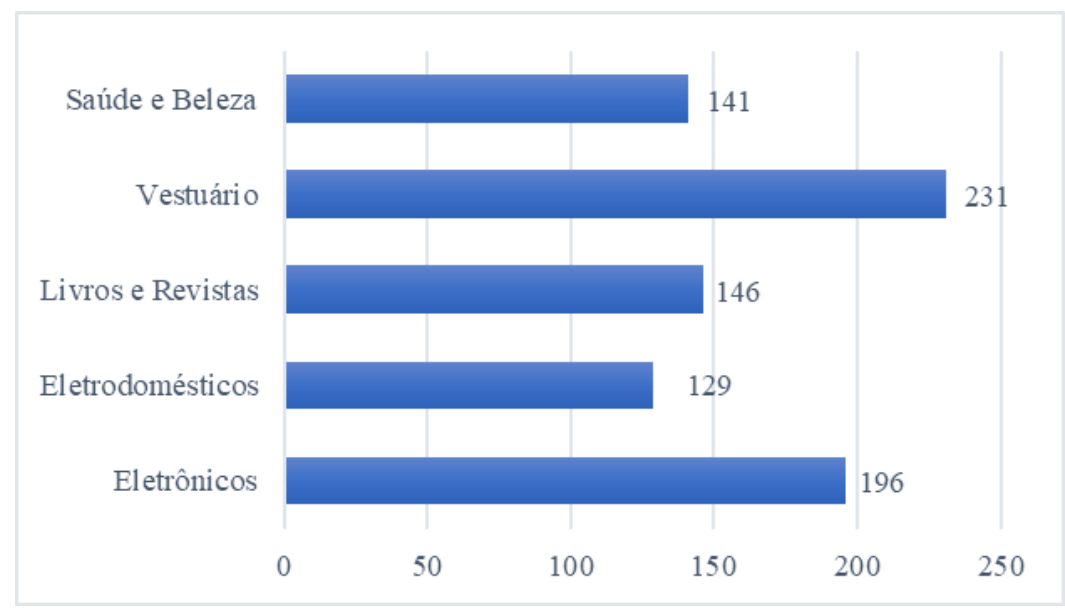

Fonte: Elaborado pelos autores com base nos dados da pesquisa.

Quanto ao tempo médio gasto navegando na internet, a pesquisa mostra que os indivíduos entrevistados em Dourados gastam uma quantidade expressiva de tempo na internet. Isso pode estar associado à crescente quantidade de opções de serviços e entretenimento acessados a partir da rede mundial de computadores. Dessa forma, a Figura 4 evidencia a predominância dos participantes da pesquisa nas duas opções com maior tempo de utilização da internet por dia, sendo 124 participantes assinalando mais de 6 horas de uso, o que corresponde a 40,6\% dos entrevistados e 121 participantes escolhendo a opção de 4 a 6 horas de uso diário, representando 39,6\% da amostra. Esses valores somados representam 80,3\% da amostra.

Figura 4 - Tempo médio de utilização da internet horas/dia, dos consumidores entrevistados em Dourados, em 2018.

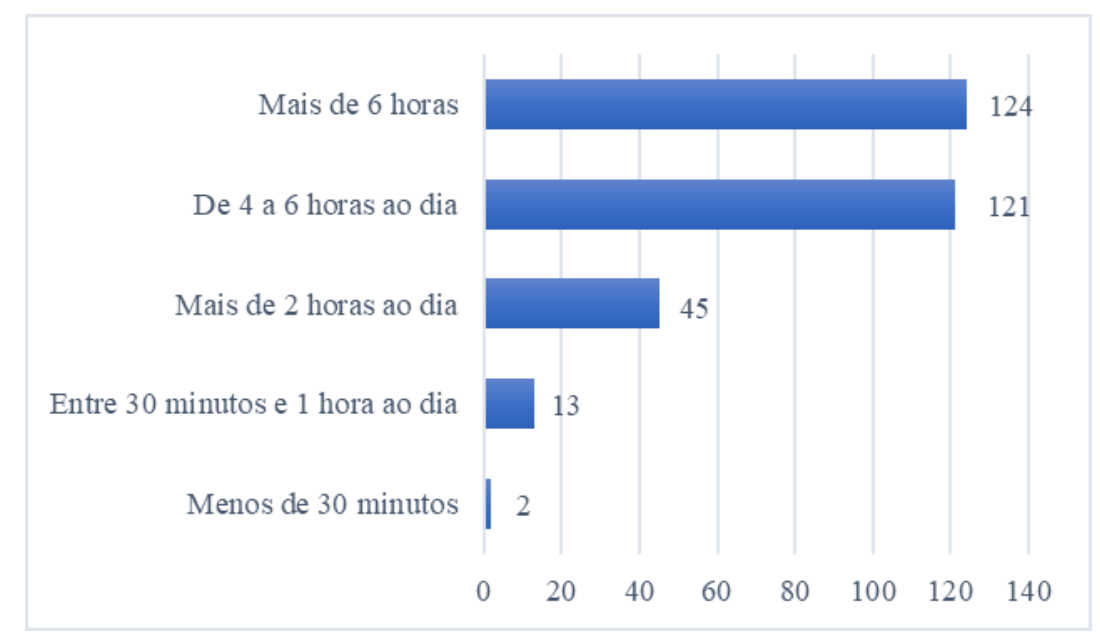

Fonte: Elaborado pelos autores com base nos dados da pesquisa.

A Figura 5 apresenta o valor médio gasto com as compras on-line. A faixa de valor médio predominante é de R\$ 201,00 a R \$ 300,00, representando 32,4\% dos participantes da pesquisa. Em seguida, tem-se a faixa de R\$101,01 a R \$200,00, com 75 participantes e, posteriormente, com 50 respostas tem-se a faixa de $\mathrm{R} \$ 301,01$ a $\mathrm{R} \$ 400,00$. Por último, representando $11,4 \%$ da amostra, tem-se os indivíduos que gastaram até $\mathrm{R} \$ 100,00$ com compras on-line. 
Figura 5 - Valor médio gasto, em reais, nas compras realizadas on-line pelos consumidores entrevistados em Dourados, em 2018 .

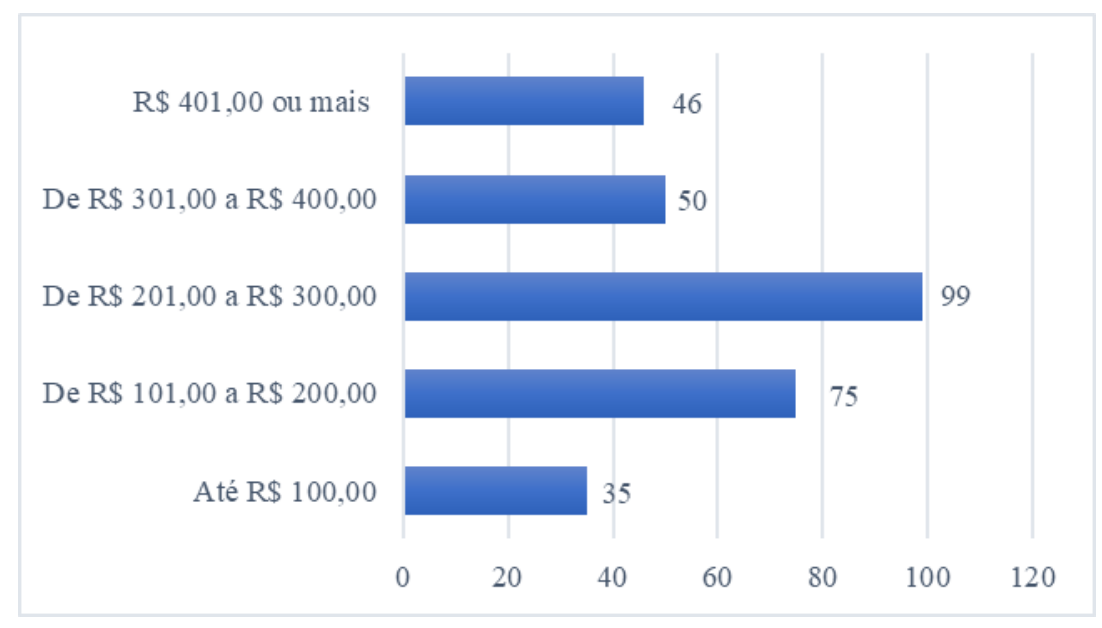

Fonte: Elaborado pelos autores com base nos dados da pesquisa.

Quando questionados sobre quais fatores influenciavam a decisão de comprar via comércio eletrônico, o item de maior relevância indicado pelos entrevistados foi amigos e membros da família, com 206 e 131 respostas, respectivamente, o que corresponde a $67,5 \%$ e $42,9 \%$ da amostra, respectivamente. As propagandas também são importantes nesse quesito uma vez que ocuparam o $3^{\circ}$ lugar em relação aos demais itens, representando 24,2\% dos participantes, conforme a Figura 6.

Figura 6 - Fatores que orientam a decisão de compra dos consumidores entrevistados em Dourados, em 2018.

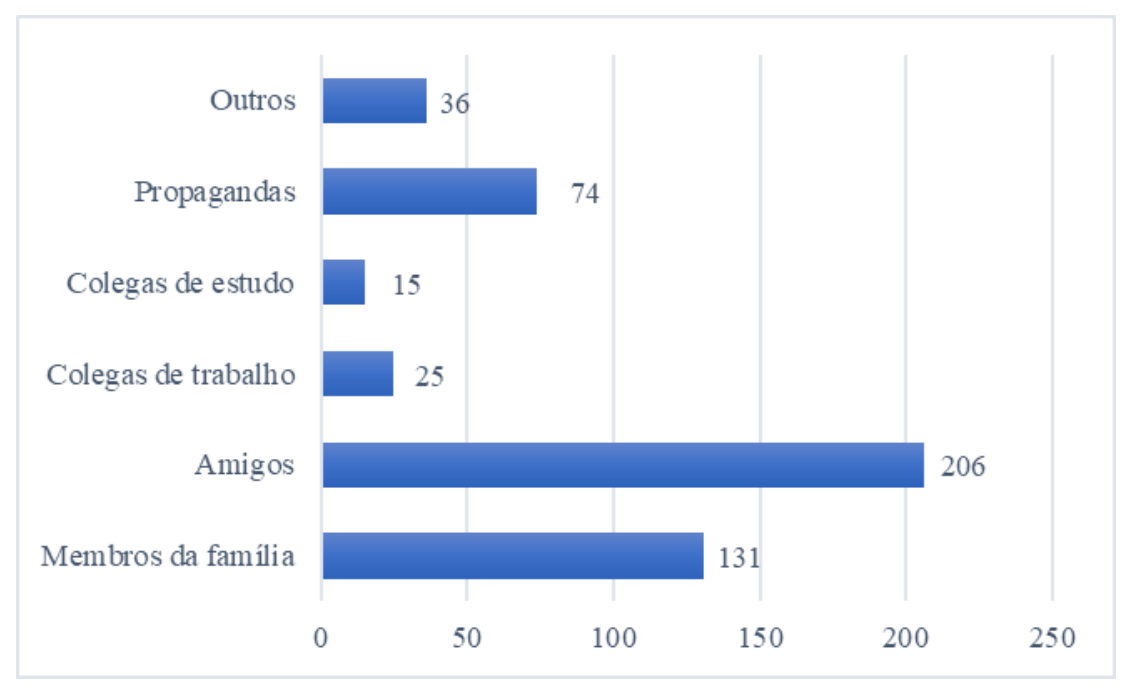

Fonte: Elaborado pelos autores com base nos dados da pesquisa.

Os indivíduos também foram questionados sobre as razões para a realização de compras via comércio eletrônico e não em lojas físicas. Nessa questão os participantes poderiam indicar mais de uma opção. A Figura 7 mostra os resultados obtidos, preço foi a resposta de 289 entrevistados, o que corresponde a 94,7\% das respostas de quem realiza compras on-line. Além disso, comodidade e praticidade também foram indicadas como elementos importantes para a realização de compras on-line, uma vez que essa foi a resposta de 199 entrevistados, isto é, 65,2\% da amostra. Em terceiro lugar, a variedade de produtos foi assinalada como fator motivador da utilização do comércio eletrônico, com 186 marcações. 
Figura 7 - Fatores que motivaram os consumidores entrevistados em Dourados a realizar compras on-line, em 2018.

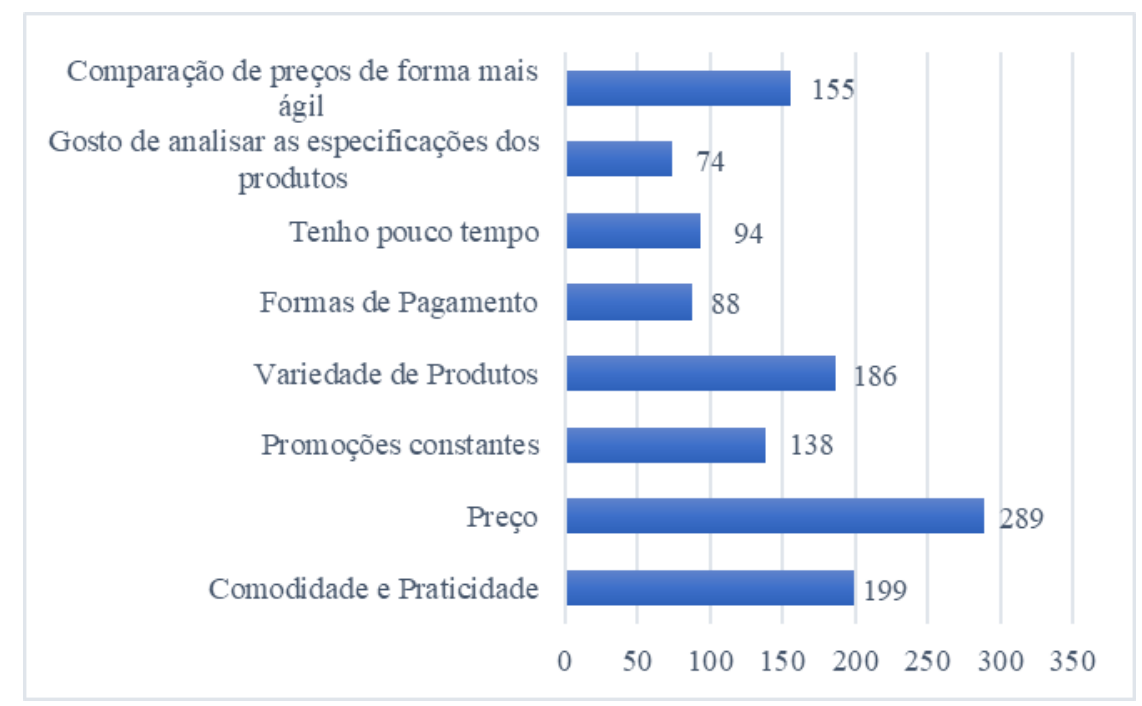

Fonte: Elaborado pelos autores com base nos dados da pesquisa.

A comparação rápida de preços, via comércio eletrônico, foi a resposta de 50,8\% dos entrevistados, sendo também um importante elemento na tomada de decisão desses consumidores. Ademais, o item "promoções constantes" também deve ser destacado, uma vez que foi a resposta de 138 entrevistados, o que representa 45,2\% das respostas. Parte disso se deve aos sites de comparação de preços, cada vez mais utilizados pelos e-consumidores.

Por fim, a Figura 8 mostra os principais motivos que desmotivaram os consumidores entrevistados a realizar compras on-line, destacando-se, dentre outras coisas, prazo de entrega, falta de contato físico com o produto e a desconfiança em relação aos vendedores e sites.

Figura 8 - Fatores que desmotivaram os consumidores entrevistados em Dourados a realizar compras on-line, em 2018.

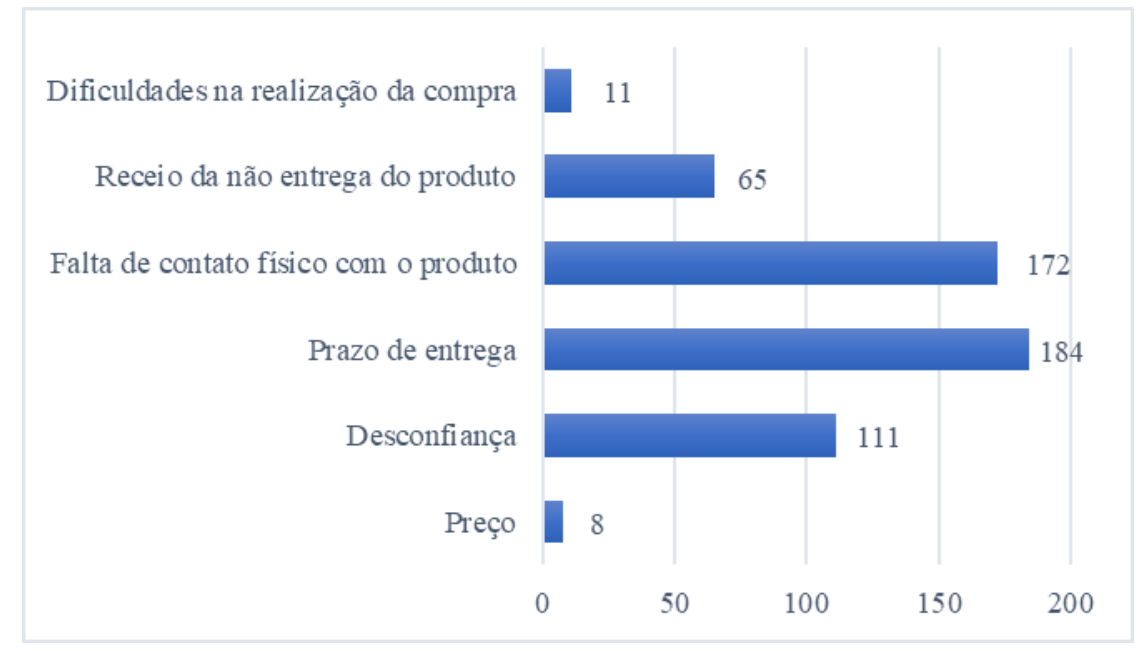

Fonte: Elaborado pelos autores com base nos dados da pesquisa.

O prazo de entrega e a falta de contato físico com o produto foram as respostas de 184 e 172 entrevistados, respectivamente. A desconfiança de alguns sites ou vendedores foi a resposta de 111 entrevistados, enquanto o receio da não entrega do produto foi mencionado 65 vezes. As dificuldades na realização da compra e o preço foram as respostas de apenas 11 e 8 entrevistados, respectivamente, sendo assim, pouco relevantes como fator desmotivador. 
Esses dados evidenciam, a partir de uma pequena amostra da população de consumidores de Dourados, o potencial existente para o crescimento do e-commerce em pequenos municípios do interior do Brasil. Nesses locais, os consumidores são muito influenciados pelas opiniões de amigos e familiares, bem como pelos preços, variedade de produtos e comodidade na realização das compras. No entanto, para que essa modalidade de comércio cresça nessas localidades, os dados indicam que as empresas que operam nesse segmento precisam aprimorar seus canais de distribuição e o pós-venda. Em especial, a troca e devolução de produtos para suprir a falta de contato com o produto, o que poderá reduzir a desconfiança dos consumidores na realização de compras on-line, como mostram os resultados obtidos.

\subsection{Resultados do Modelo Logit}

Este estudo teve como objetivo analisar os determinantes da tomada de decisão dos consumidores entre comprar bens e serviços em lojas físicas ou em lojas virtuais. Para isso, foi realizada uma pesquisa de campo no município de Dourados (MS). Os dados coletados foram utilizados na realização de uma análise econométrica, cujo modelo escolhido foi o logit. A Tabela 3 mostra os resultados do modelo estimado, o qual possui uma variável dependente binária, que nesta aplicação indica se o consumidor já realizou ou não alguma compra on-line.

$\mathrm{Na}$ tabela são apresentados os efeitos marginais das variáveis independentes (gênero, idade, cor, estado civil, renda e escolaridade) sobre a variável dependente (já ter realizado compras on-line). Dessa forma, a segunda coluna da Tabela 3 mostra o efeito marginal da variável independente em questão sobre a probabilidade de o consumidor já ter realizado alguma compra on-line. As colunas 3 e 4 apresentam o erro padrão e o teste $Z$, que foram utilizados para determinar a significância estatística das variáveis independentes. Esta análise foi realizada com nível de significância de 5\%.

Tabela 3 - Efeitos Marginais sobre a probabilidade de o participante utilizar ou não o comércio eletrônico.

\begin{tabular}{l|l|l|l}
\hline Variáveis Explicativas & Efeito Marginal & Erro Padrão & $\mathbf{z}$ \\
\hline Masculino & $-0,0176535$ & 0,03736 & $-0,47$ \\
\hline Idade de 20 a 25 anos & 0,05033190 & 0,05135 & 0,98 \\
\hline Branco & 0,05042120 & 0,04000 & 1,26 \\
\hline Solteiro & $0,18729030^{*}$ & 0,03905 & 4,80 \\
\hline Renda de R\$ 1.000,00 a R\$ 2000,00 & $0,09723550^{*}$ & 0,03623 & 2,68 \\
\hline Ensino Superior Completo & $0,18316010^{*}$ & 0,03055 & 6,00 \\
\hline
\end{tabular}

Nota: * significante a $1 \%$. Fonte: Elaborado pelos autores com base nos dados da pesquisa.

A Tabela 3 mostra que as variáveis estado civil, renda e escolaridade são estatisticamente significantes, enquanto as variáveis gênero, idade e cor não são estatisticamente significantes. Com relação aos sinais, a variável gênero é única que afeta negativamente a probabilidade de o indivíduo ter realizado alguma compra on-line.

Como todas as variáveis independentes utilizadas possuíam várias categorias, optou-se por agrupar essas categorias em apenas dois grupos. Neste caso, quando se analisa, por exemplo, a variável estado civil, estamos comparando os indivíduos que são solteiros com todos os outros indivíduos da amostra. Dessa forma, o resultado encontrado mostra que para indivíduos solteiros, a probabilidade de comprar on-line aumenta em 18,72\%. Já para indivíduos com renda entre $\mathrm{R} \$ 1.000,00$ a $\mathrm{R} \$$ $2.000,00$ a probabilidade aumenta em $9,72 \%$ e, se esse indivíduo possuir ensino superior completo a probabilidade aumenta em $18,31 \%$.

Com relação às outras variáveis, além dos efeitos marginais não serem muitos altos, elas também não foram estatisticamente significantes. Portanto, as variáveis que possuem mais influência sobre a escolha do indivíduo em utilizar ou não o comércio eletrônico são: estado civil, renda e escolaridade. 
Assim, os resultados mostram que há espaço para o crescimento do e-commerce, sobretudo se ele explorar determinados nichos de mercado. Esse é o caso do público composto por consumidores solteiros, como maior nível de renda e instrução. Nesse caso, o modelo indica a possibilidade de crescimento expressivo nesses mercados, o que pode ser implementado através de produtos e serviços elaborados para atender as necessidades deste grupo. No entanto, outros grupos de consumidores também podem ser alcançados uma vez que amigos e familiares exercem muita influência na decisão de comprar via internet, como mostrado anteriormente. Nesse sentido, as estratégias comerciais devem ser elaboradas de forma a atingir, mesmo que indiretamente, outros grupos de consumidores.

\section{Considerações Finais}

Este artigo analisou a tomada de decisão dos consumidores de Dourados entre comprar no comércio eletrônico ou em lojas físicas. Os principais resultados desta pesquisa indicam que a renda dos indivíduos tem maior peso na decisão de comprar pela internet, a qual atrai os consumidores por oferecerem preços mais atrativos.

Com a análise descritiva dos dados é possível identificar o perfil de compra dos consumidores de Dourados, onde mais da metade dos entrevistados declarou ter renda de até $\mathrm{R} \$ 2.000$ reais e mais de $60 \%$ confiam em realizar compras on-line. Entretanto, a maioria dos entrevistados não confia em fornecer seus dados pessoais para realizar essas compras. Quando questionados sobre a confiança na entrega do produto, $70 \%$ dos entrevistados afirmaram confiar na entrega.

Dos 384 entrevistados, 305 deles, representando 79\% da amostra, realizam compras on-line. Dentre eles, a maioria compra poucas vezes ao ano, comprando mais produtos das categorias vestuários e eletrônicos, cujo valor médio das compras foi entre $\mathrm{R} \$ 201,00$ e R \$300,00. Os consumidores entrevistados utilizam a internet, em média, por mais de 6 horas, o que mostra a presença direta da tecnologia no dia a dia desses indivíduos.

$\mathrm{O}$ estudo também analisou os fatores que motivam e desmotivam os participantes a realizar compras on-line. $\mathrm{O}$ fator mais indicado como motivador para a utilização do comércio eletrônico foi o preço, o que evidencia a preocupação dos indivíduos em se adequar às suas restrições orçamentárias, isso, ao buscarem o melhor preço para os produtos desejados. Comodidade, praticidade e variedade dos produtos também foram destacados como elementos importantes na tomada de decisão acerca das compras pela internet.

Dentre os fatores críticos que desmotivaram a utilização do comércio eletrônico pode-se destacar o prazo de entrega, assinalado por 184 participantes. Mesmo que os dados indiquem que $70 \%$ da amostra confia na entrega do produto, o prazo até o recebimento do produto e a falta de contato físico são considerados fatores desmotivadores. $\mathrm{O}$ fator desconfiança foi indicado por 111 participantes como desmotivador para a realização de compras on-line.

A partir dos dados obtidos também foi possível realizar a aplicação do modelo logit, o qual teve como variáveis estatisticamente significativas: estado civil, renda e escolaridade. Os resultados mostraram que indivíduos solteiros aumentam em $18,72 \%$ a probabilidade da realização de compras on-line, enquanto possuir uma renda de $\mathrm{R} \$ 1.000,00$ a $\mathrm{R} \$ 2.000,00$ pode aumentar essa probabilidade em 9,72\% e possuir ensino superior completo aumenta as chances de comprar on-line em 18,31\%.

Com os resultados obtidos pode-se concluir que apesar do comércio eletrônico ainda gerar certa desconfiança para algumas pessoas, ele teve boa aceitação dos consumidores douradenses. No entanto, em trabalhos futuros sugere-se analisar outros aspectos dos resultados obtidos, por exemplo, o perfil de compras de indivíduos de diferentes faixas de renda. Ainda, como o cenário econômico vigente tem afetado as transações via internet, entre outros.

\section{Agradecimentos}

Os autores agradecem o suporte financeiro da Universidade Federal da Grande Dourados (UFGD) e da PROAP/CAPES. 


\section{Referências}

Almeida, D. F. (2015). A tributação do comércio eletrônico nos Estados Unidos da América e na União Europeia. Almedina.

Angelo, C. F. \& Silveira, A. G. (2000). Finanças no varejo. Atlas.

Assunção, W. S., Fagundes, P. F. \& Révillion, A. S. P. (2019). Comércio eletrônico. Sagah.

Castells, M. (2003). A galáxia da internet - reflexões sobre a internet, os negócios e a sociedade. Zahar.

Coelho, L. S., Oliveira, R. C. \& Alméri, T. M. (2013). O crescimento do e-commerce e os problemas que o acompanham: a identificação da oportunidade de melhoria em uma rede de comércio eletrônico na visão do cliente. Revista de Administração do Unisal, 3 (3), 63-85.

Costa, G. C. G. (2007). Negócios Eletrônicos - uma abordagem estratégica e gerencial. Ibpex.

Costa, S. C. B. \& Ruiz, J. M. (2011). Comércio Eletrônico. Revista Eletrônica Novo Enfoque, 13 (13), 150-157.

E-bit. (2020). 42 Relatório Webshoppers. https://company.ebit.com.br/webshoppers/webshoppersfree

E-bit. (2021). 43ª Relatório Webshoppers. https://company.ebit.com.br/webshoppers/webshoppersfree

Figueiredo, I. L. (2009). Histórico do Comércio Eletrônico. www.oficinadanet.com.br/artigo/1718/historico_do_comercio_eletronico

Freire, M. C. M. \& Pattussi, M. P. (2018). Tipos de estudo. In: Estrela, C. (Org.). Metodologia científica: ciência, ensino, pesquisa. Porto Alegre: Artes Médicas, 109-127.

Galinari, R., Cervieri Junior, O., Teixeira Junior, J. R. \& Rawet, E. L. (2015). Comércio eletrônico, tecnologias móveis e mídias sociais no Brasil. BNDES Setorial, 41 (41), p.135-180.

Gujarati, D. (2006). Econometria básica. Elsevier.

Hall, R. E. \& Liberman, M. (2003). Microeconomia Princípios e Aplicações. Pioneira Thomson Learning.

Hoffmann, R. (2006). Estatística para Economistas. Cengage Learning.

Ibge (2018). Instituto Brasileiro de Geografia e Estatística. Acesso à internet e à televisão e posse de telefone móvel celular para uso pessoal 2018. https://biblioteca.ibge.gov.br/visualizacao/livros/liv101705_informativo.pdf

Macedo, D., Kovaleski, J. L., Betim, M. T. \& Matos, S. N. (2013). Comércio eletrônico: identificação do perfil do e-consumidor. Revista da Fae, 1 (16), 90103.

Mankiw, N. G. (2020). Introdução à Economia. Gengage.

Mansfield, E. \& Yohe, G. (2006). Microeconomia. Saraiva.

Novaes, S. F. \& Gregores, E. M. (2007). Da Internet ao Grid: a Globalização do Processamento. Unesp.

Pitwak, A. C. \& Ferreira, C. L. (2009). A utilização do E-commerce como diferencial das organizações para a conquista de mercado. (Trabalho de Conclusão de Curso) - Faculdade de Telêmaco Borba, Brasil.

Siqueira, J. P. L. (2004). A Internet e o varejo: uma análise dos interesses da oferta e preferências dos consumidores. [Tese de Doutorado em Administração] - Universidade de São Paulo, SP, Brasil. https://www.teses.usp.br/teses/disponiveis/12/12139/tde-06012006-171459/publico/Tese_JP.pdf

Testa, M. G., Luciano, E. M. \& Freitas, H. (2006). Comércio Eletrônico: tendências e necessidades de pesquisa. Revista ANGRAD, 7 (1), $23-42$.

Turban, E., Rainer Jr., R. K. \& Potter, R. E. (2003). Administração de tecnologia de informação: teoria e prática. Campus.

Varian, H. R. (2021). Microeconomia: Uma Abordagem Moderna. Atlas.

Vieira, V. A. (2010). Mensuração da qualidade de serviço no varejo eletrônico e seu impacto sobre as intenções comportamentais. Revista de Administração de Empresas, 50 (2), 199-214.

Wooldridge, J. M. (2016). Introdução à econometria: uma abordagem moderna. Cengage Learning. 